\title{
El dominio público y los bienes públicos: Europa y América Latina. ¿El hijo sigue mirando al padre?
}

López Ramón, F. \& Vignolo Cueva, O. (2015). El dominio público en Europa y América Latina. Lima: Círculo de Derecho Administrativo.

\section{SeRgio ChemÁs}

\section{RESUMEN}

El estudio del derecho de los bienes públicos en América Latina y en Colombia es algo todavía poco desarrollado. Se sigue mirando hacia el derecho comparado para obtener respuestas, tal como un hijo mira a su padre, porque fue allá donde surgieron los grandes desarrollos del tema. El dominio público en Europa y América Latina es producto de un encuentro entre varias autoridades en el tema de los bienes públicos tanto de Europa como de América Latina. Esta reseña se divide en tres partes: i) un breve análisis de derecho comparado frente al concepto de dominio público; ii) la identificación de los contenidos más interesantes e innovadores de los regímenes de bienes públicos, y iii) un ejercicio académico para que el lector lo desarrolle al leer el libro.

Palabras clave: bien público, derecho comparado, dominio público, demanialidad (dominialidad) pública, desestatización, función pública y ecológica de la propiedad.

1 Asistente investigador del Departamento de Derecho Administrativo, Universidad Externado de Colombia, Bogotá, Colombia. Correo-e: sergio.chemas@uexternado.edu.co Fecha de recepción: 19 de julio de 2015. Fecha de modificación: 24 de septiembre de 2015. Fecha de aceptación: 10 de octubre de 2015. Para citar el artículo: Chemas, S. (2015). El dominio público y los bienes públicos: Europa y América Latina. ¿El hijo sigue mirando al padre? Revista Digital de Derecho Administrativo n. ${ }^{\circ}$ 14, Universidad Externado de Colombia, pp. 223-236. DOI: http://dx.doi.org/10.18601/21452946.n14.11 


\title{
Public domain and public goods (land) in Europe and Latin America: Does the boy still look up to his father?
}

\author{
ABSTRACT
}

The study of the regulation of public goods in Latin America and in Colombia is somewhat precarious. There is still a tendency to look for answers in comparative law, similar to when a boy looks up to his father, mainly because the concepts now under analysis where developed abroad. The Public Domain (land) in Europe and Latin America is the product of an academic colloquium of various authorities in the subject of public goods. This critical review paper is divided into three parts: i) a brief summary of comparative law analysis of the concept of public domain (land), ii) a presentation of the most innovative ideas in certain law systems, and iii) an academic exercise to be completed by the reader of the book.

Keywords: Public good, Comparative Law, public domain (land), public domainization, destatization, public and ecological function of property.

El estudio del derecho de los bienes públicos en América Latina y en Colombia es algo todavía poco desarrollado (Pimiento \& Santaella, 2015, p. 313). Se sigue mirando hacia el derecho comparado para obtener respuestas tal como un hijo mira a su padre, porque fue en Europa donde surgieron los grandes desarrollos del tema.

El libro reseñado es producto de un encuentro entre varias autoridades en el tema de los bienes públicos tanto de Europa como de América Latina, el cual tuvo lugar en Santiago de Chile en el año 2015. El libro El dominio público en Europa y América Latina se publicó como el primer proyecto de investigación académica comunal de la Red Internacional, y busca no solo correr la voz de lo contenido en él sino también consolidar la Red. Esta iniciativa brindaría no solo el empuje y desarrollo que requiere el tema de los bienes públicos (casi intacto por la academia) en cada una de las Universidades que contribuyeron, permitiendo un espacio de intercambio internacional, para debatir, contribuir y escuchar ideas académicas, sino también a los respectivos países.

En la presente reseña se busca preservar y a la vez exponer el hilo guía del libro: "identificar el origen de la noción de dominio público y la manera en la que ha evolucionado hasta la época presente" y "la profundización, por parte de los ordenamientos latinoamericanos, sobre los elementos determinantes de la formación, trayectoria y significado actual del dominio público" (López Ramón, p. 19), a la vez tratando de abarcar con voz propia algunos de los temas 
expuestos, siempre teniendo en mente evitar quitarle la sorpresa de las ideas del libro al lector. Para ello, la reseña se ha dividido en tres partes.

Una primera, en la que se adelanta un breve análisis de derecho comparado frente al concepto de dominio público, tratando la figura no solo en su país de origen sino también en Latinoamérica. En la segunda parte, se identifican algunos de los contenidos más interesantes e innovadores de los regímenes de bienes públicos que más captan la atención. Y la tercera parte intenta esbozar un ejercicio académico para que el lector lo desarrolle al leer el libro.

\section{PARTE 1. LA BÚSQUEDA POR LA NOCIÓN DE DOMINIO PÚBLICO EN LA ACTUALIDAD}

\section{ORÍGENES}

La noción de dominio público nace en Francia, siendo su mayor exponente Proudhon, quien, "tomando como punto de partida la clasificación romana que diferenciaba entre los bienes intra commercium y extra commercium, distingue entre dominio público y dominio privado del Estado" (De Guerrero Manso, 2015, p. 49), llegó a la conclusión de que el Estado ejerce solamente facultades de guardia y custodia sobre los bienes públicos, sustentándose en el derecho de soberanía.

Teoría que claramente creció y evolucionó en el mismo derecho francés, pero sin desviarse, por lo que casi dos siglos después se sigue edificando doctrinariamente sobre la misma base. Existen, empero, avances jurisprudenciales que se dieron a lo largo del siglo XIX frente al concepto de dominio público, en los que se "admit[ió] primero el carácter de bienes públicos de los bienes destinados al uso del público y, segundo, [se] concedió ese mismo carácter a los asignados a un servicio público" (Alcarraz, 2015, p. 30), consolidando así el grueso de los cambios que se han dado al concepto de dominio público en Francia. (Ahondaremos más en este tema en las partes 2 y 3 ).

El primer ordenamiento que adoptó la doctrina francesa del dominio público fue el español. La doctrina francesa del dominio público llega a España en 1850, gracias a Colmeiro, quien había adoptado la tesis de Proudhon, y con la acogida de la misma por la academia española se consolidó el concepto. En vista de ello, para la doctrina española de aquel entonces, el dominio público operaba sobre los bienes públicos ${ }^{2}$ y se sustenta exclusivamente en el derecho de soberanía. Doctrina esta que no duraría mucho tiempo sin ser alterada, pues a continuación surgiría una tesis minoritaria francesa que cambiaría el concepto

2 Concepto que para España en ese momento consistía en las cosas que corresponden en plena propiedad a la Nación y en cuanto al uso a todo el mundo -es decir, pertenecer a todos los hombres en común. 
de dominio público en España. El exponente de esta tesis fue Hauriou, y la tesis básicamente consistió en sostener que la relación Estado-bienes de dominio público se fundamenta en el derecho de propiedad, y no en el de soberanía.

Es así como el derecho español y el derecho francés parten caminos, cada uno yendo por su propio sendero. ¿Será que hoy día, con ocasión de cambios legislativos, jurisprudenciales y doctrinarios, han vuelto a caminar de la mano? La respuesta se debe buscar en el texto.

\section{DESCENDENCIA}

Si lo anterior sucedió entre derechos de dos países colindantes, cabe imaginar qué pasó cuando el dominio público atravesó el Atlántico. ¿Qué habrá sucedido con el concepto de dominio público al llegar a los diferentes ordenamientos jurídicos de América Latina? ¿Habrá sido incorporado a los diferentes ordenamientos jurídicos? En caso de que que así sea, ¿mantendrá el mismo significado originario francés? Adicionalmente, se debe enfatizar que este concepto no llegó a ser positivado en un medio virgen, sino todo lo contrario, pues ya en Latinoamérica se manejaban las fuentes del antiguo derecho romano, conceptos de derecho alemán e italiano y doctrina divergente francesa, por lo que el resultado final probablemente no fue el mismo del concepto originario. Es necesario subrayar que para este momento en la lectura, quien lee debe comparar derechos, pues con la lectura de los capítulos del libro se vuelve esencial tener de presente que hay tanto diferencias conceptuales en el uso del término como de su semántica.

A continuación se reseña brevemente el régimen colombiano, y luego se procede a hacer unas breves reflexiones sobre el tema.

\section{Julián Pimiento y Héctor Santaella, La Persistente Rebeldía DE COLOMBIA FRENTE AL DOMINIO PÚBLICO}

El dominio público como categoría jurídica en Colombia, no nació.

El derecho colombiano no es de aquellos que siguieron la lógica francesa o española $[\ldots]$

El dominio público como una categoría jurídica no fue acogido por el ordenamiento jurídico nacional (Pimiento \& Santaella, p. 313).

En definitiva, pareciera ser que desde un comienzo los autores en cita dejan clara la postura que ha acogido el derecho de bienes colombiano. Sin embargo, aparentemente la rebeldía no es tan sencilla, pues "pese a esta falta de arraigo y de desarrollo conceptual, la noción de dominio público no ha sido del todo ajena a la jurisprudencia, la doctrina, ni al Derecho positivo en Colombia" (p. 314). A lo largo del artículo los autores retan las afirmaciones previas, 
adentrándose en el estudio de los diferentes aspectos del dominio público en Colombia: su formación, trayectoria y el sentido actual del concepto.

Parte de la exposición de los autores se encamina a demostrar que la jurisprudencia de las altas cortes colombianas ha propuesto variadas definiciones del concepto de dominio público. El único problema es que se ha tratado el dominio público como sinónimo de cuatro nociones distintas. De esas cuatro, de lejos, la más interesante por improbable es la del dominio público sinónimo de bienes fiscales (p. 325). En una oración, lo que dice esta vertiente de la jurisprudencia es que, en vista de que la figura del dominio público acepta el contenido económico, debe entonces estar asociada con los bienes fiscales, y por el hecho de no tener contenido económico, el dominio eminente con los bienes de uso público. La anterior afirmación denota una confusión frente a nociones básicas del derecho de bienes públicos: lastimosamente es probable que haya sido fruto de una mala extrapolación del derecho comparado, pues confunde no solo el concepto de dominio público, sino también los de dominio eminente y bien fiscal (colombiano), y limita innecesariamente los bienes de uso público. Es importante reconocer que este es el propósito de la Red Internacional de Bienes Públicos, buscar y unificar los conceptos dentro del espectro de los países miembros, o por lo menos tener la noción clara en cada uno de los países.

De lo anterior, es evidente que no hay consenso ni mucho menos precisión ante la noción de dominio público en Colombia. Lo que conduce a preguntar: ¿qué es lo que hay actualmente en nuestro ordenamiento jurídico? Los autores proponen que "Nuestro derecho conoce la propiedad pública $[\ldots]$ reconoce la posibilidad de su uso directo por parte del público $[\ldots]$ bienes que tienen el carácter de inalienables, inembargables e imprescriptibles. Tampoco es ajeno al servicio público" (p. 330).

Es decir que se tienen los mismos componentes esenciales que en la teoría clásica francesa, incluso reconociendo "las contraposiciones entre el dominio público y el dominio privado" (p. 331), hasta el punto de poder decir que en Colombia el dominio público es para la propiedad pública como el dominio privado es para la propiedad privada.

De forma abstracta y general, esto puede probar que aun habiendo hecho uso de otras fórmulas doctrinarias y sin haber acogido las vertientes francesas ni españolas en nuestro derecho de bienes, llegamos a las mismas conclusiones que los franceses con su dominio público.

Sin embargo, el artículo obedece a un análisis de rigurosidad, que manteniendo posturas bastante fundamentadas desarrolla esta temática a mayor profundidad. Eso sí, se debe advertir, puede que al finalizar la lectura del artículo se arribe a la conclusión de que el derecho de bienes públicos colombiano sigue siendo rebelde sin causa. 
Ahora bien, la disertación realizada por los autores a lo largo del libro permite que el lector se haga una idea de la recepción del concepto de dominio público en los diferentes regímenes latinoamericanos.

Puede que en algunos regímenes se haya incorporado una noción de dominio público semejante a la original francesa; que en otros, simplemente se tengan los rezagos de la misma. También, hay la posibilidad de que el concepto ni siquiera haya llegado a algunos regímenes. Lo cierto es que, al haber partido de un análisis abstracto, pues no se ha realizado la clasificación específica de cada uno de los regímenes, no se puede llegar a una conclusión del tema, ni es del interés de la reseña.

El ejercicio realizado por los autores de la obra, a la vez que brinda muchos frutos a nivel de derecho comparado (al punto de permitir que algún intrépido realice la comparación detenida de los regímenes), también funge de prueba fehaciente de lo difícil que puede llegar a ser el estudio del derecho de bienes. Pues el académico, para entender su propio derecho de bienes, tiene que partir del detallado análisis empírico de factores como las evoluciones históricas, tanto de las colonias como de los reinados, de las legislaciones vigentes como de las derogadas, de los desarrollos jurisprudenciales hito como también de los erróneos; todo esto, para que cuando lleguen los temas de actualidad, él sepa cómo hacerles frente e interpretarlos. En otras palabras, para que pueda mirar y entender el porqué de su propio régimen y poder explicar el mañana del mismo.

\section{PARTE 2. LAS INNOVACIONES EN EL DERECHO COMPARADO DE LOS BIENES PÚBLICOS}

En esta parte se analizan algunos de los regímenes más interesantes con la finalidad de examinar las más recientes innovaciones en el ámbito del derecho de bienes públicos.

IgNACIO M. DE LA Riva y JuAN CARLOS CASSAGNe, Y FiguRAS INNOVADORAS DESDE el Río DE LA Plata

Los citados autores empiezan por explicar el origen continental del derecho argentino, el fuerte influjo de la doctrina francesa, y al igual que en Colombia, la fuerte influencia del derecho romano, lo que permite catalogar al derecho de bienes argentino como un régimen híbrido.

Una vez abarcados los temas generales del derecho de bienes en Argentina, los autores examinan figuras innovadoras como la propiedad fiduciaria de los bienes públicos (que todavía posa cuestiones y retos), la especial situación de los recursos naturales (en específico al dominio originario), y los derechos reales administrativos. Por la brevedad que debe mantener una reseña solo podrá 
recaer la mirada en las innovaciones de la doctrina argentina frente a la propiedad fiduciaria de los bienes públicos.

De entrada, el problema jurídico es el siguiente: "¿Puede el Estado, al constituir un fideicomiso, transferir a un tercero la propiedad fiduciaria sobre bienes del dominio público?" (De la Riva \& Cassagne, 2015, p. 241).

Pregunta cuya respuesta es un no rotundo dentro del derecho argentino (y sería igual para el colombiano), posición que es prácticamente unánime por parte de la doctrina argentina.

Sin embargo, los autores no permiten que esto detenga su aventurada postura y se preguntan si cabría la posibilidad de que, resguardando la titularidad estatal y manteniendo la destinación de uso público del bien, se pueda transferir el dominio fiduciario del mismo: "Estamos pensando en el hipotético caso de un fideicomiso bajo el cual se vede al fiduciario toda posibilidad de disponer o gravar el referido bien, donde el beneficiario sea el pueblo, y en cuyo marco se designe al Estado como fideicomisario (beneficiario final) a quien será restituido el bien a la extinción del fideicomiso" (p. 273).

O la otra posibilidad: "podría pensarse que dado el carácter instrumental y temporal del dominio fiduciario, su transferencia supondría, per se, un acto de disposición no necesariamente incompatible en todos los casos con la inalienabilidad de los bienes del d emanio" (p. 271). (De la Riva \& Cassagne, 2015).

De todos modos, ante la primera fórmula, por más resguardo que tenga el bien público, cabe la posibilidad de que sobre él recaigan deudas, momento en el cual se vería la inutilidad de la figura, pues la posibilidad de que se lleve a cabo una ejecución o una enajenación forzosa sobre un bien público es en lo mínimo complicado. Y la segunda posibilidad equivaldría a decir "voy a fracturar para luego enyesar de otra manera el concepto de inalienabilidad del bien público".

Pero, lo importante para la reseña no es entrar en los detalles específicos de esta figura para determinar si cabría lo propuesto, no en este momento por lo menos, sino aclamar el espíritu aventurero del texto al tratar de crear herramientas que estimulen una visión más de mercado y de economía cambiante para los bienes públicos. En el caso concreto, no perder de vista las ventajas que una figura como el fideicomiso conllevaría "a la explotación más eficiente de los bienes públicos" (p. 272), es ganancia.

\section{HUberT ALCARRAZ Y LAS FIGURAS QUE BUSCAN AMPLIAR LA DEMANIALIDAD}

Se retoma el caso francés para exponer brevemente dos teorías de reciente positivización: la demanialidad ${ }^{3}$ global o demanialidad pública por accesoriedad, y

3 Término proveniente del derecho francés, que antes de ser traducido al español se escribe "dominialidad". Significa: "patrimonio en el seno del poder público". 
la demanialidad virtual. Para ello, se tiene que ubicar el lector en el año 2006 con la expedición del Código general de la propiedad de las personas públicas, pues en él "se agrupan las principales normas relativas a los bienes públicos" (Alcarraz, p. 40). Estas han sido denominadas por el autor como los símbolos de la elasticidad, dado su innegable empuje hacia el acrecentamiento de los bienes pertenecientes al dominio público.

Empezando por la demanialidad virtual, basta con citar lo que el artículo dice de la figura:

La voluntad puede también consistir en aumentar el alcance del dominio público. Es decir que la noción de dominio público demuestra una elasticidad notable durante las últimas décadas. Normalmente, hasta que la asignación o el acondicionamiento no sean realizados, el bien no pertenece al dominio público $[\ldots]$ [sin embargo] las jurisdicciones contencioso administrativa francesas ampliaron los principios del dominio de las personas públicas hacia los inmuebles todavía no asignados ni acondicionados (p. 40).

En segundo lugar, la teoría de la demanialidad pública global o por accesoriedad, que representa una teoría de acumulación y simplificación procedimental, que consiste en que "[integra] en el dominio público la totalidad de una obra pública, incluso sus partes no destinadas al uso del público o a un servicio público, porque considera que constituye un conjunto funcional" (p. 42).

"Su efecto es igualmente el de aumentar el ámbito de aplicación de la demanialidad pública" (p. 43), dice el autor. Por tanto, es innegable que las innovaciones en el derecho francés de los bienes públicos apuntan hacia la ampliación de la unidad demanial.

\section{Alejandro VERGARA BLANCO Y EL SINSENTIDO DE DECLARAR LA PROPIEDAD ESTATAL}

En Chile "se dejó atrás la infértil discusión sobre la propiedad estatal de los recursos naturales" (Vergara Blanco, 2015, 303). ¿Qué significa esto? Para Vergara, lo que más resalta de la ordenación de los bienes del derecho chileno es que este se alejó del derecho comparado hace más o menos 30 años, es decir, ya no obedece a la lógica europea del dominio público. Pero, ¿qué argumentos tiene el autor para afirmar lo anterior?

Tan pronto se adentra el lector en este artículo halla un espíritu de novedad, ni siquiera de un ordenamiento híbrido, sino hasta más bien, de rebelión, de rechazo por ideas del pasado, un movimiento hacia el neo-modernismo del derecho. Es decir, se entra con influjos de curiosidad a descubrir la nueva modalidad con la que los chilenos están viendo los bienes estatales.

Fue con la Constitución Política de la República de Chile de 1980 (CPR) que se dio paso a la nueva ordenación de los recursos naturales y los bienes públicos, 
la cual 20 años después habría logrado que se fortaleciera el acceso a las extracciones de los recursos naturales y consecuentemente el aprovechamiento de los mismos. Pero aún más importante, lograría que se perdiera el sinsentido de declarar la propiedad estatal sobre los recursos naturales, y más bien pasaría a la ampliación de la regulación "para que estén disponibles, con justicia, igualdad, equidad y razonabilidad, a todos los potenciales usuarios y explotadores audaces y cuidadosos" (Vergara Blanco, 2015, p. 303). Este movimiento los chilenos lo han denominado la desestatización de los recursos naturales.

Para el autor, y aparentemente para Chile, "la estatización es anti-histórica, está [más] que pasada de moda" (p. 306), dado que de nada sirve que el Estado se ponga en la tarea de declarar como de propiedad o dominio estatal las variedades de recursos o de bienes de significación social. De hecho, la CPR lo prohíbe y garantiza a los ciudadanos que el Estado no se pondrá en esas, pues con el nuevo orden constitucional quedó establecida la summa divisio de los bienes, eliminando la propiedad estatal de los mismos ${ }^{4}$.

A renglón seguido el texto brinda un ejemplo, ante el cual, cualquiera que sepa de la importancia de la industria pesquera en Chile entenderá sus dimensiones y los efectos que tiene este tipo de regulación a nivel microeconómico, pues es exactamente con la Ley de regulación de la Pesca (2013) que el autor planea explicar el fenómeno de la desestatización de los bienes públicos.

El punto principal a resaltar de la citada ley es que "el Congreso Nacional no requería auto-declarar al Estado como propietario de los peces" (p. 307). Lo anterior es colosal, pues significa un replanteamiento de cómo el Estado tiene que identificarse frente a los bienes, ya no necesitando declarar su propiedad, ni su demanialidad, sino su potestad para regular, en otras palabras, establecer que es el Estado el que tiene la potestad de regular los recursos hidrobiológicos y sus ecosistemas, y de otorgar autorizaciones.

Lo importante para la tendencia desestatista "es lograr que la legislación de bienes y recursos naturales sea más coherente, que busque una observación más atenta de la realidad", porque al fin y al cabo el ejemplo anterior denota es el uso del sentido común, es decir, "lo que hay detrás de [la Ley de Pesca] es el reconocimiento implícito de que los peces son res nullius, de nadie. No se necesitaba declararlos propiedad de alguien para regular su extracción, es que los peces no son apropiables" (p. 308). Pero tan solo pensar en las trabas que se habrían creado de haberse legislado de otra manera horroriza, estremece, conmueve y hasta espanta.

Procederemos ahora a examinar el caso colombiano.

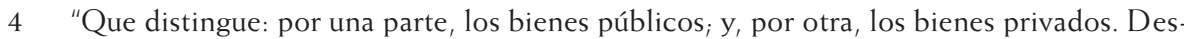
aparecen de nuestro sistema la propiedad o dominio estatal de bienes y recursos altamente significativos; pues o son públicos (de todos, del pueblo; y nunca estatales) o son privados (dentro de estos cabe considerar a los de particulares, del fisco, regionales, de municipios)" (Vergara Blanco, 2015, p. 307). 
Héctor Santaella y Julián Pimiento, una función no tan EN PRO DE SU PÚBLICO

El artículo 58 de la Constitución Política colombiana consagra la función pública y ecológica del derecho de propiedad. Esto "ha supuesto una transformación notable de la relación entre el dominio privado y la atención de las necesidades de interés general" (Pimiento \& Santaella, 2015, p. 335).

Desde su proclamación en el texto constitucional, esta figura ha tenido desarrollos jurisprudenciales que han llevado a "distintos tipos de limitaciones, deberes, cargas y condiciones para el ejercicio del derecho" (p. 336).

Gracias al desarrollo jurisprudencial, la función pública ha pasado de ser una figura orientadora a detentar un poder de delimitación, que ha conducido a que el instituto de la expropiación adquiera el carácter de secundario y excepcional (p. 337). Al ser una figura de menor complicación (que, por ejemplo, la expropiación), desde hace ya unos 10 años se ha venido incrementando su incorporación en diversas áreas del derecho de bienes, como por ejemplo en materia urbanística, ambiental, de turismo, entre otras ${ }^{5}$.

Pero "con gran poder vienen grandes responsabilidades", y como con cualquier creación jurídica colombiana que no se reglamenta bien, la figura cayó en desproporcionalidad. En la actualidad "se han ensanchado los márgenes de conformación", hasta el punto de limitar la potestad de enajenar un bien privado por consideración de índole de función social y ecológica.

Lo que tiene que entrar a analizar el ordenamiento jurídico colombiano es la precisión de los límites que la misma Carta le ha formulado a la figura, evitando así que la figura siga encarrilada a convertirse en una expropiación ilegal, improvisada y sin posibilidad de indemnización.

\section{PARTE 3. EJERCICIO ACADÉMICO, HIPÓTESIS Y TEMA TRANSVERSAL DEL LIBRO}

En los aportes académicos realizados por los autores se hallan afirmaciones, pistas de la existencia de un tema transversal del libro: las corrientes reformadoras que buscan la ampliación o reducción de la unidad dominial dentro de los diferentes ordenamientos jurídicos.

Teniendo como finalidad promover un buen ejercicio académico se ha enfocado esta tercera parte hacia el desarrollo de una hipótesis referente al tema, que consiste en una afirmación general y dos subcuestiones que sirven para dar claridad metodológica a la búsqueda. La general reza: ¿Será que en gestion de riesgos, desarrollo rural, minería y prestación de servicios públicos". 
Europa, a diferencia de lo que está sucediendo en América Latina, se está dando un fenómeno de ampliación de la unidad dominial, es decir, de los bienes públicos en cabeza del Estado?

Y las subcuestiones, ¿Será que en Francia se está dando un fenómeno de ampliación de la unidad dominial? ¿Será que en América Latina se está dando un fenómeno de reducción de la unidad dominial?

Conviene subrayar que se ha utilizado el caso francés para el planteamiento de la primera subcuestión debido a la gran cantidad de indicios que se encuentran en el artículo de Hubert Alcarraz, por lo que este permite proporcionar una tentativa de respuesta a la hipótesis.

\section{LA MISIÓN DEL DERECHO FRANCÉS POR AMPLIAR LA DEMANIALIDAD PÚBLICA}

El surgimiento del patrimonio público de la República, y con ello la consolidación de la unidad dominial ${ }^{6}$, fue esencial para la construcción del Estado francés, pero, caún es así?

Desde un comienzo el autor afirma que la evolución del derecho de bienes públicos francés ha ido en procura de la ampliación de la demanialidad (Alcarraz, 2015, p. 28). Ya conociendo la posición que asume el artículo, será más fácil identificar y estudiar los argumentos del autor, para que luego, a partir de ello, cada quien pueda arribar a una conclusión frente a la hipótesis.

En la segunda parte se hizo mención al Código general de la propiedad de las personas públicas de 2006, y a la manera como este sirvió para clarificar la categorización de los bienes públicos y para cerrar el debate doctrinario y jurisprudencial sobre los bienes dedicados a los servicios públicos. Este momento en la evolución de los bienes públicos en Francia sirve para determinar la intención de la administración de limitar o acrecentar el dominio público.

Al proporcionar una solución al debate, el Código de 2006 deja ver la intención de la administración al establecer que "[La] exigencia de un acondicionamiento imprescindible (para la ejecución de las funciones del servicio público al cual el bien es destinado) sustituye a la condición elaborada por la jurisprudencia, que requería un acondicionamiento no 'imprescindible' pero sí 'especial', lo que parece ser menos severo"' (p. 38).

Lo anterior significa que la postura de acrecentar el dominio público se ve un poco borrosa al considerar que la norma establece criterios más rigurosos, limitando sustancialmente los bienes que pueden llegar a ser valorados como públicos bajo este nuevo acondicionamiento.

Pero no habiendo terminado su exposición, el autor trae a colación lo que ha sucedido con posterioridad a la expedición del Código: "No obstante la verdad es que pocas decisiones jurisdiccionales han tenido en cuenta ese 
cambio, y ocho años después de la reforma legislativa, no estamos seguros de que vaya a producir todas sus potencialidades" (p. 39).

Lo anterior corrobora la frase de J. E. Portalis: "los hombres cambian más fácil de dominación que de leyes" (Pimiento \& Santaella, 2015, p. 317).

Es así como cada lector tendrá que determinar qué tiene más peso: la existencia jurídica de la norma o la ineficacia de la misma. Es decir, el hecho de que las decisiones jurisdiccionales ignoren la norma y continúen reconociendo la atribución de bien público a los bienes acondicionados de forma "especial" para el servicio público, da a entender que las funciones administrativas y jurisdiccionales están trabajando hacia un acrecentamiento, o por lo menos no permitiendo la disminución, del dominio del Estado sobre los bienes públicos.

Otra particularidad a tener en cuenta es la de las dos figuras analizadas en la segunda parte (demanialidad virtual y demanialidad global), pues con su reciente positivización es claro que la voluntad del legislador es la de ampliar la demanialidad pública o por lo menos facilitar el proceso para su conformación.

Para concluir con este breve análisis de la postura del derecho francés, y para aventurar una respuesta a la primera subcuestión planteada, se debe decir que es indudable el movimiento reformador de ampliación de la unidad dominial en Francia. El porqué de ello no es claro, pero puede que sea que para los franceses es esencial tener un fuerte patrimonio público al manejo del Estado.

Ya teniendo una potencial respuesta a la hipótesis, el resto del ejercicio académico quedará en cabeza del lector. Es él quien deberá hacer la comparación entre el derecho europeo (que claramente no solo consiste en el caso francés) y el derecho latinoamericano. Sin embargo, no sería del todo osado aventurarse a decir que en América Latina encontrará movimientos abismalmente más consolidados que buscan la desestatización y consecuente reducción a la unidad dominial del Estado.

\section{BIBLIOGRAFÍA}

Alcarraz, H. (2015). El dominio público francés frente a la Modernidad. En El dominio público en Europa y América Latina. Lima: Círculo de Derecho Administrativo.

Alessandri Rodríguez, A. \& Somarriva Undurraga, M. (1974). Curso de Derecho Civil. De los bienes y derechos reales. Santiago: Editorial Nascimiento.

Chevallier, J. (2011). El Estado Posmoderno. Bogota: Universidad Externado de Colombia.

Claro Solar, L. (1980). Explicaciones de Derecho Civil cbileno y comparado, tomo 6, De los bienes. Santiago: Imprenta Cervantes.

Covilla, J. C. (2014). Autorizaciones y concesiones en el derecho administrativo colombiano. Bogotá: Universidad Externado de Colombia. 
De Guerrero Manso, C. (2015). Bases históricas y constitucionales del dominio público en España. En El dominio público en Europa y América Latina. Lima: Círculo de Derecho Administrativo.

De la Riva, I. M. \& Cassagne, J. C. (2015). Formación, trayectoria y significado actual de dominio público en la Argentina. En El dominio público en Europa y América Latina. Lima: Círculo de Derecho Administrativo.

DíEZ, M. M. (1987). Dominio público (Teoría general y régimen jurídico). Buenos Aires: Abeledo.

GARZÓN, A. O. (ed.). (2013). Los grandes fallos de la jurisprudencia administrativa colombiana. Bogotá: Universidad Externado de Colombia.

Gaudemet, Y. (2008). Droit Administratif des biens. Paris: LGDJ.

López Ramón, F. (2015). Presentación del libro. En El dominio público en Europa y América Latina, p. 514. Lima: Círculo de Derecho Administrativo.

Marienhoff, M. (1975). Tratado del dominio público. Buenos Aires: Tipografía Editora Argentina.

Pimiento Echeverri, J. A. (2011). Reflexiones en torno a la división de los bienes públicos en el Código Civil. Revista de Derecho Privado 21, pp. 207-232.

Pimiento Echeverri, J. A. (2012). Teoría de los bienes de uso público. Bogotá: Universidad Externado de Colombia.

Pimiento, J. (2015). Derecho Administrativo de Bienes. Bogotá: Universidad Externado de Colombia.

Pimiento, J. \& Santaella, H. (2015). Estado actual del "dominio público" en el derecho colombiano. En El dominio público en Europa y América Latina, p. 514. Lima: Círculo de Derecho Administrativo.

RinCÓn CÓRDOBA, J. I. (2012). Planes de ordenamiento territorial, propiedad y medio ambiente. Bogotá: Universidad Externado de Colombia.

SANTAELla, H. (2010). El régimen constitucional de la propiedad privada y su garantía en Colombia. Madrid, Tesis doctoral defendida en la Universidad Autónoma de Madrid.

Santaella, H. (2011). Notas sobre el concepto y la garantía de la propiedad en la Constitución colombiana. Revista de Derecho Privado 21, pp. 237 ss.

Vergara Blanco, A. (1989). La Teoría del dominio público: el estado de la cuestión. Revista de Derecho Público 114, pp. 27-58. 
Vergara Blanco, A. (2015). Derecho de bienes públicos en Chile. Recuento doctrinario y actualidad normativa. En El dominio público en Europa y América Latina. Lima: Círculo de Derecho Administrativo. 